Association for Information Systems AIS Electronic Library (AISeL)

MCIS 2009 Proceedings

Mediterranean Conference on Information Systems

(MCIS)

2009

\title{
Customer Relationship Management Adoption: Using A Dynamic Capabilities Approach
}

Cristiane Pedron

, ISEG - Instituto Superior de Economia e Gestão, cdpedron@iseg.utl.pt

Mário Caldeira

caldeira@iseg.utl.pt, caldeira@iseg.utl.pt

Follow this and additional works at: http://aisel.aisnet.org/mcis2009

\section{Recommended Citation}

Pedron, Cristiane and Caldeira, Mário, "Customer Relationship Management Adoption: Using A Dynamic Capabilities Approach" (2009). MCIS 2009 Proceedings. 119.

http://aisel.aisnet.org/mcis2009/119

This material is brought to you by the Mediterranean Conference on Information Systems (MCIS) at AIS Electronic Library (AISeL). It has been accepted for inclusion in MCIS 2009 Proceedings by an authorized administrator of AIS Electronic Library (AISeL). For more information, please contact elibrary@aisnet.org. 


\title{
CUSTOMER RELATIONSHIP MANAGEMENT ADOPTION: USING A DYNAMIC CAPABILITIES APPROACH
}

\author{
Pedron, Cristiane, ISEG - Instituto Superior de Economia e Gestão, Miguel Lupi 20, 1249078 \\ Lisboa, Portugal, cdpedron@iseg.utl.pt \\ Caldeira, Mário, ISEG - Instituto Superior de Economia e Gestão, Miguel Lupi 20, 1249078 \\ Lisboa, Portugal, caldeira@iseg.utl.pt
}

\begin{abstract}
Customer Relationship Management (CRM) adoption is both a relevant research topic in academia and a challenge for practitioners. We understand CRM as a complex concept that includes technology, strategy and philosophy. In this research, we propose an analysis of CRM organisational dynamic capabilities. The main goal is to apply a dynamic capabilities perspective to analyse how companies can improve their CRM initiatives. In order to achieve this purpose, a qualitative, interpretative, case-based research strategy was implemented. We conducted a case study in a Portuguese telecommunication enterprise for one year. The case study was based on semi-structured interviews and document analysis. We used qualitative techniques to analyse the collected data and ground our interpretation in a dynamic capabilities theoretical approach. We propose a theoretical framework related to CRM dynamic capability that is corroborated with empirical evidence. We believe that because organisations which adopt a CRM strategy are in a competitive environment, a dynamic model needs to be used to analyse and explain how they can improve their CRM strategy in order to achieve success.
\end{abstract}

Keywords: Customer Relationship Management, Dynamic Capabilities, Case Study, Telecommunication Sector

\section{INTRODUCTION}

Customer Relationship Management (CRM) has been adopted by companies as a way to obtain a competitive advantage and maintain a close relationship with customers (Payne 2006). The concept of Dynamic Capabilities has received rapid recognition as a potential source of achieving and sustaining competitive advantage in organisations (Zahra et al. 2006, Eisenhardt \& Martin 2000, Teece et al. 1997). Barney (1991, p.102) notes that an organisation is said to "have a competitive advantage when it implements a value creating strategy not simultaneously being implemented by any current of potential competitors".

Dynamic Capabilities is a conceptual framework that is widely accepted in the literature (Teece 2007). It focuses on the capability of resource reconfiguration (Helfat et al. 2007, Eisenhardt \& Martin 2000). In Penrose's (1959) research we can observe the spirit of dynamic capabilities: new combinations of resources lead to innovation and economic value creation. Although the concept of dynamic capability has been criticised as tautological, endlessly recursive and non operational (Priem \& Butler 2001), we follow the idea of Makadok (2001) and Bhatt and Grover (2005) who claim that this approach is appropriate for the analysis of organisational initiative related to customer relationship. Sustainable development of a CRM strategy depends on different organisational capabilities. Plakoyiannaki and Tzokas (2002) argue that proposing a list of critical CRM capabilities is a challenging goal, since they are derived from several bodies of literature and need to be further articulated for development within the organisation. 
According to Payne (2006, p.22) CRM is "a strategic approach concerned with creating improved shareholder value through the development of appropriate relationship with key customers and customer segments. CRM unites the potential of Information Technology (IT) and relation marketing strategies to deliver profitable, long-term relationships." Payne (2006) argues that the most important CRM feature is providing enhanced opportunities to use data and information, both to understand customers and implement better relationship marketing strategies. The IT allows the cross-functional integration of people, operations, processes and marketing capabilities. In this paper we understand CRM as a complex concept that includes technology, strategy and philosophy.

The objective of this paper is to analyse (1) which dynamic capabilities should be developed in a CRM initiative and (2) how companies can deal with organisational dynamic capabilities related to CRM. In order to answer these questions we have conducted a case study in a Portuguese telecommunication company. This paper is organised in five sections. Following this introduction we present a theoretical discussion on dynamic capability and customer relationship management. After that the research method and the case study are described and discussed. Finally, we propose a CRM dynamic capability approach and analyse the main findings.

\section{DYNAMIC CAPABILITIES: A CRM PERSPECTIVE}

Some authors began the discussion about the importance of a company's capabilities in the adoption of CRM (Day 2000, Dibb \& Meadows 2004, Plakoyiannaki \& Tzokas 2002). In order to adopt and manage a CRM initiative, organisational processes are being constantly thought over (Gibbert et al. 2002). According to Bohling et al. (2006), change management is crucial for achieving success in a CRM initiative.

The relationship between a company and a customer can be considered unique. However this relationship can be influenced by many company-customer dyad actions held over time. Cultivating each relationship with a customer can be understood as an organisational dynamic capability. Information Technology helps organisations conduct relationships with customers. Ciborra (2002) proposed the term cultivation in order to deal with technological infrastructure. This author highlights that IT artefacts have a life of their own and people must find ways to live with them. Ciborra (2002) argues that companies must find alternative practices that do not demand intensified use of technology. We believe that companies can use IT to cultivate customer relationship but, at the same time, offer a customer something that exceeds a "computer-based relationship".

According to Teece (2007), an organisational dynamic capability can be continually created, expanded, innovated, protected, and can maintain an organisational resource as unique and relevant in a company. Many of these movements of resources are induced by the external environment that a company is inserted in. Customer relationship management must take into account that this "relationship" occurs in an ecosystem with various actors. We cannot analyse the relationship between a company and its customers without considering all the elements of the ecosystem.

Teece (2007) refers to "ecosystem" as the environment where the relationship between company and its customer is being developed. A lot of actors are present in an ecosystem, e.g., competitors that also be looking for the development of a close, long, and profitable relationship with customers. The suppliers are critical actors in the same environment. A good relationship with suppliers enables the firm to secure the necessary resources to support the development of products and services. Another relevant actor is the regulating authorities that have power to influence the relationship between the customer and the company, for example by defining quality patterns or helping consumers to defend their rights. One more important actor in this environment is the perspective customer. This kind of customer could buy some goods or services in a company but does not maintain an active relationship with the organisation. 
There is an important link between dynamic capabilities and organisational processes. Teece et al. (1997, p.524) argue that "dynamic capability is resident in the firm's organisational processes". According to Maritan (2007), dynamic capabilities are about changes, and organisations use various processes (search processes, decision-making processes, management processes, etc.) in order to identify the need or opportunity for change.

Plakoyiannaki and Tzokas (2002) proposed a list of CRM critical processes: (a) creating a corporate culture conducive to customer orientation, learning and innovation; (b) making customer value a key component of the corporate strategy and planning process; (c) collecting and transforming customer data to aid strategic and operational decision making; (d) appreciating, identifying and nurturing knowledge creation, dissemination and use within the organisation; (e) developing clear market segments and customer portfolios; ( $f$ ) defining, developing and delivering the value proposition; ( $g$ ) using campaign and channel management as part of the valuable proposition; and ( $h$ ) measuring performance at each stage of the process to navigate decision making. Each process related to a CRM strategy needs to be improved over time in an organisation. We believe that CRM adoption and CRM management processes are unique for each company. Hence, we consider "path dependence" and "dynamic capabilities" as lenses to explore this phenomenon.

According to Teece et al. $(1997$, p.515) one of the ideas of the central dynamic capability theory is that capabilities emerge from a series of path-dependent learning experiences. As the authors claim, "At any given point in time, firms must follow a certain trajectory or path of competence development. This path not only defines what choices are open to the firm today, but it also puts bounds around what its internal repertoire is likely to be in the future". Therefore, we agree that adaptation to a changing environment poses a critical challenge for the development of a firm's capabilities.

Observing arguments presented by Raman et al. (2006) and Plakoyiannaki and Tzokas (2002), we shall identify the categories of organisational capabilities which may influence the success of CRM implementation.

\subsection{Learning and market orientation capabilities}

Plakoyiannaki and Tzokas (2002) suggest that market orientation and learning capabilities are deeply embedded in the CRM system, customer insight generation and knowledge discovery, value, and performance measurement processes. It is crucial to emphasise that mistakes also play a significant role in the evolution of dynamic capabilities (Eisenhardt \& Martin 2000). Over the last years, many companies have tried to adopt CRM and in many cases they have failed (Peppers \& Rogers 2004). Although major failures raise barriers that block learning, the companies sometimes learn from these mistakes and improve their CRM adoption process.

Raman et al. (2006) proposed organisational learning as an antecedent to the successful implementation of CRM. They based their research on previous academic work that demonstrated some basic characteristics: (1) developmental and group behaviour displayed by employees to promote continuous learning within an organisation; (2) the removal of knowledge barriers through learning, and (3) organisational learning in the context of technical training available, technical expertise, and the level of knowledge of the innovation.

\subsection{Integration capabilities}

According to Plakoyiannaki and Tzokas (2002), CRM is an organisation-wide investment that seeks to maximise the value delivered to the customer by personalising offerings. It implies that customers begin to use multiple channels, as they may buy one product from the salesperson and another from the web site. As a result, Shoemaker (2001, p.178) claims that "it becomes more difficult and more important to manage the customer relationship seamlessly, presenting a consistent image, service level, and message however the customer chooses to participate". A customer has many ways to interact with the 
firm: sales force, retailer/wholesaler partners, call centre, web site and fax services, as well as receiving promotional messages from advertisements, direct mail and shopping channels.

Campbell (2003) believes that other relevant factors of integration in the company are related to marketing and the IT department. While marketing requires the development of external capabilities to link a firm with its customers, technology development is an internal capability that sustains a firm's market position. The author claims that this similarity between marketing and IT may be achieved through different organisational mechanisms, ranging from informal communication linkages to joint committees and project teams or cross-functional integration.

\subsection{Analytical capabilities}

Analytical capabilities are linked to technological artefacts and knowledge, and they play an active role in enhancing relationships with customers (Plakoyiannaki \& Tzokas 2002). This capability shows that while customer data are readily available through existing CRM database software packages, data alone do not lead to customer knowledge.

Knowledge about customer capability is based on generating and integrating customer information throughout the organisation. It is not inimitable, "because the processes of generating and integrating customer knowledge are embedded in organisational cognitive activities and are not observed readily from outside, and immobile, because these processes are created within the firm and cannot be purchased in the market" (Campbell 2003, p.376).

\subsection{Operational capabilities}

Plakoyiannaki and Tzokas (2002) state that operational capabilities apply and enhance resources. According to them, these capabilities are skills developed at functional and administrative levels that translate customer information into service offerings.

CRM packages play an important role in facilitating the integration between the customer and the firm, "enabling the firm to coordinate all the points of communication to present the customer with the desired image, message, and information" (Shoemaker 2001, p.177). The author states that time management and communication functions, such as scheduling and e-mail capability, are often incorporated into CRM systems.

\subsection{Direction capabilities}

Direction capabilities are related to the achievement of CRM objectives. In a CRM initiative companies perform "customer-centric orientation" (Raman et al. 2006). It consists of an organisational structure and processes focused on customers rather than functional areas (Day, 2000). Its main goal is to keep the organisation's attention on customer interactions and ensure that expertise from different functional areas is deployed to promote the quality of customer experience.

From our point of view, "direction capabilities" in a CRM initiative have to take the following into account (Campbell 2003): (1) the importance of building teams across all functional areas of the firm; (2) the involvement of senior management; (3) the organisational values: these values play a significant role in creating customer knowledge competence and they are dependent on the active participation of all employees; (4) the method used to evaluate employees' performance reflects how companies really understand CRM.

\section{METHODOLOGY}

An interpretative case study in a large Portuguese telecommunication company was conducted. The main objective was to observe how the company deals with CRM organisation dynamic capability. The company was chosen because it faces market pressures, has a large customer base, it has been 
significantly investing in a CRM strategy and heavy uses CRM technology. Moreover, the company have adopted the CRM strategy for more than five years, which is important for the analysis of the organisational dynamic nature and the evolution of CRM stages.

Case study in the IS area is justified by the distinctive need to understand complex social phenomena. Walsham (1993) states that interpretive methods are concerned with generating understanding of the IS context and the process, whereby the IS influences and is influenced by its context. According to Stake $(1995$, p.135), a qualitative case study is highly personal research. The author claims that researchers "are encouraged to include their own personal perspectives in the interpretation. They way the case and the researcher interact is presumed unique and note necessarily reproducible for other cases and researchers".

As we do not impose our outsiders' a priori understanding on the situation and try to understand phenomena through the meanings that people assign to them, the interpretative approach was applied in this research. We assume that our knowledge of reality is gained only through social construction such as language, consciousness, shared meanings, documents, tools, and other artefacts (Orlikowski \& Baroudi 1991, Klein \& Myers 1999).

Following Walsham (2006, p.323), who states that interviews are "a part of most interpretive studies as a key way of accessing the interpretations of informants in the field", we used interviews as the main source of data collection. Twenty five managers of the firm were interviewed, in 2008, through the use of semi-structured interviews. All participants were interviewed individually on a face-to-face basis. The interviews took place in the companies and lasted between 1 and 3 hours each. The interviewees include: a member of the board of directors, the Chief Information Officer, the CRM project champion (a top manager of the organisation), and several other managers in information systems, sales and marketing. Each interviewed was recorded. We also collected documents about CRM project available in the firm were collected. Other secondary materials were taken from the company's website and from the media.

Data was coded and analysed by the use of software for qualitative data analysis - NVivo. It facilitates structuring data without losing much information. The time spent transcribing the data enabled the researchers to gain a deep knowledge about the statements provided by each interviewee, making them easier to find, analyse and compare.

\section{CASE STUDY}

Alfa Telecom is a large Portuguese telecommunication company. The company has a diversified business portfolio and it has participated in a very dynamic market. In 2006, the largest company of the holding received a Public Tender Offer, which was rejected by the shareholders. In the same year, another company of the holding passed through a spin off process, which reinforced the competition in the country.

After these changes, the dynamics of the company's internal environment changed and the top managers have been trying to reorganise the company in order to quickly return value to the shareholders, customers, suppliers, employees and other stakeholders. The managers are concerned with the fast evolution of the telecommunications sector and the future competition in the domestic market, which now has a new competitive company. CRM initiatives - such as customer care and retention programs - have been planned in the company.

\subsection{CRM perspective}

Alfa Telecom adopted a CRM business approach in 2002. The initiative was an answer to market changes and the need to improve competitiveness. The sales manager claims that twenty years ago the company had people that paid to receive the telecommunication service and nowadays the company 
has customers. She highlights that these customers have more information and more demands each day.

Initially, a group of people was formed to develop a CRM project. Some people with experience in CRM implementation in the telecom industry were hired by the firm. A consulting CRM company was also contracted to help the company. The main objective of the CRM adoption team was to change the company mentality (strategy, culture, structure, processes, routine, etc.) from a product orientation to a customer focus.

In the first years, top management delegated power to CRM groups and supported them in order to introduce new ideas in the company. Since the introduction of CRM initiatives the company had had four different CEOs (Chief Executive Office) with different perspectives on the relevance of CRM to the company. Due to this, changes were forced on the location of CRM within the organisational structure and on the importance of IT in CRM adoption.

The IT manager believes that "Probably there are more than 30 concepts related to CRM in this company". Although some of the managers in the CRM area claimed that CRM means a philosophic way of treating customers in order to help a company maintains a good relationship with customer and not the technology. It was possible to observe a strong effort made in relation to technological aspects while little importance was given to customer relationship issues. According to the customer relationship manager, CRM is the organisational capacity of becoming familiar with the customer (name, needs, behaviour, products consumed, etc.), in order to differentiate him/her from other customers and to offer a personalised solution (product and service).

\section{CRM business processes}

Alfa Telecom has a large customer base, which shares in residential and business customers. Despite a very complex path related to the customer relationship, the company knows that it must improve customer relationship capability. The employees need quality customer information and must have the competence to deal with this information, in order to maintain a profitable relation with customer, claims one interviewee.

In the beginning of the CRM project, Alfa Telecom contracted a CRM consultant company. This consultant company developed a CRM implementation methodology that followed four steps: (1) identifying and knowing customers, having information available for characterising each customer's needs; (2) differentiating, creating solutions suitable for each one's needs; (3) interacting, improving communication with the customers to understand their needs; and (4) personalising, respecting each customer's individuality.

We interviewed the call centre manager to know his opinion on quality services and evolution in Alfa Telecom's call centre. He explained that the call centre is outsourced, and, although Alfa Telecom knows that operators receive technical and behavioural training, this is the responsibility of a partner enterprise. For people that work in "out bound" positions, such training is short because they only need some explanations on how to use the system and how to follow the script guide while talking to a customer. These operators receive a list of customers' names and the products' characteristics that they sell. The operators that work in "in bound" positions receive more attention because of the complexity of the task. They have more information about customers and in some cases they know customer value and use the "next best activity" technology developed by the customer relationship department.

In the call centre manager opinion, outsourcing the call centre is a challenge because it is difficult to motivate the operators that generally work part time for the company only for earn money. The turnover in the call centre does not allow quality improvement. In order to improve this situation, Alfa Telecom created control activities (e.g. Alfa Telecom people listen to a customer's conversation in order to check if the operator is using the right procedures) and a mechanism to provide incentives for the 
operators (e.g. parties, gifts, etc.). But the manager of customer contact channel says that the call centre in outsourcing is a necessity suggested by the market. If the company needs more people in order to answer a new sales campaign, this situation does not represent a fixed cost to Alfa Telecom.

\subsection{Information system for CRM}

In the CRM department, IT is mainly seen as a way to allow the company to maintain a close and frugal relationship with a customer, however in the IT department some of the people are not much concerned about the "relationship with customer". They know that Alfa Telecom is the market leader and do not believe in relationship customer strategy to be more competitive. For them, the new CRM software is important to obtain operational efficiency.

In relation to CRM systems, different initiatives took place at the same time. One software was developed in-house to attend to residential customers and another on from Siebel was adopted to attend to business customers. According to one IS interviewee, CRM software emerged from various types of software developed to solve the needs of the business sector. Each business sector had its own information system and a database. As a result of these technological initiatives and the history of the company (acquisitions and mergers), nowadays Alfa Telecom has problems related to customer data quality. There are several customer databases, with low data integrity. The problems arose when the company observed the need to have all information integrated. In 2007, a new (significantly different) Siebel release was being implemented in order to organise company data and to address some of their internal problems. With these different CRM systems people in the company complain about customer data quality. The customer contact channel manager argues that without quality customer data, people in the marketing and sales sector cannot build customer relationship strategies.

Alfa Telecom has been trying to adopt new CRM software in order to integrate all its channels. More than one project aimed at Siebel adoption has been launched in the last three years. The dynamics of the external environment induced internal changes and the CRM project was also affected. According to the customer relationship department manager, even though the IS department has tried to involve the business department, this involvement could be improved. As Alfa Telecom has many ongoing processes and not all of them are documented, people spend a lot of time verifying these organisational processes, which may not be complete.

We have interviewed two managers of the department of "organisational processes". They claim that organisational processes are expected to be planned before choosing the CRM information system. Nevertheless, the department of organisational processes and information system department have not worked together until now. They know that the alignment between information system and organisational processes is very important and there is a new project going on where both departments will none together.

\section{CRM DYNAMIC CAPABILITY FRAMEWORK}

Teece (2007) proposes a framework to develop an organisational dynamic capability. Our purpose is to develop a similar framework for a CRM dynamic capability, using the CRM concepts and the empirical evidence collected in the case of Alfa Telecom. We adopt Coltman's (2007, p.303) CRM capability concept: "CRM capability represents deliberate and persistent investments in a combination on human, technical, and business related capabilities". The author highlights that CRM capabilities are difficult to measure because they are intricate organisational and are dependent from organisational processes.

Figure 1 presents a theoretical model with meta-dynamic capabilities which make a "CRM Dynamic Capability". Each meta-dynamic capability is presented in detail considering Alfa Telecom evidence. 

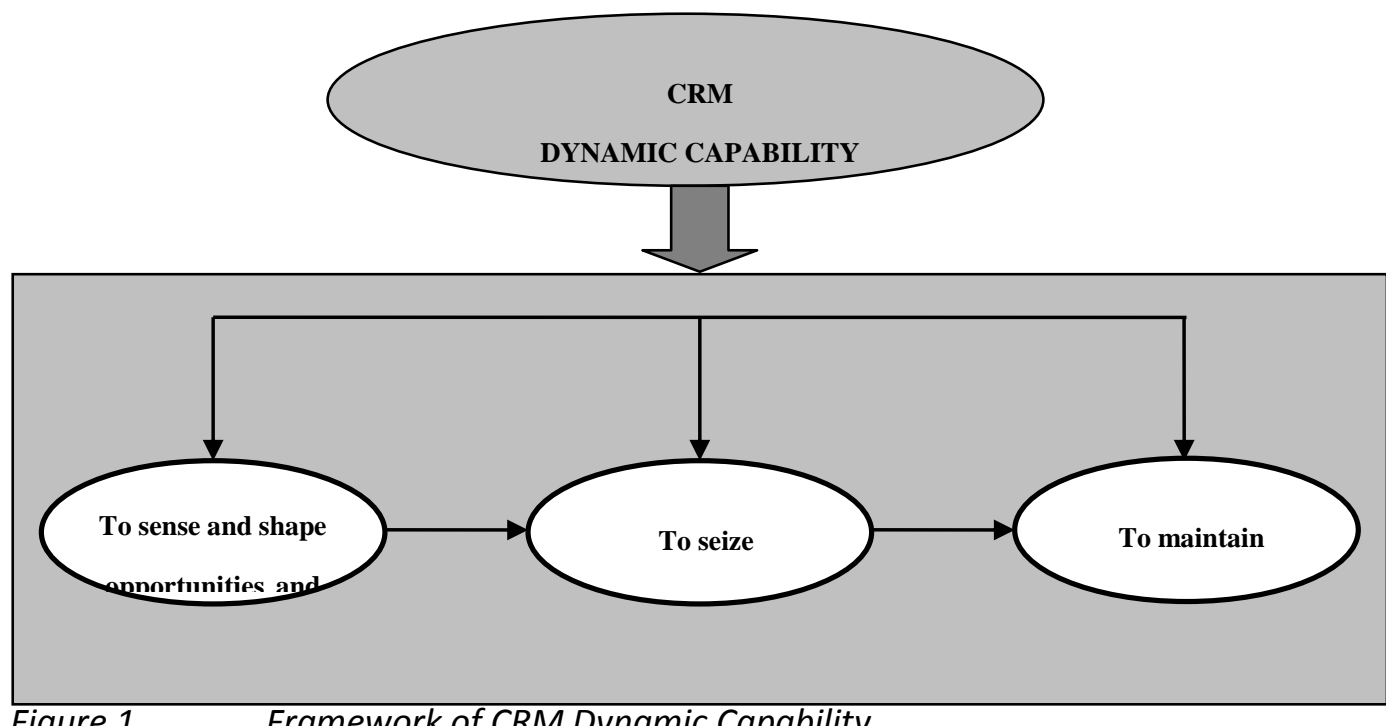

Figure 1. Framework of CRM Dynamic Capability

\subsection{To sense and shape opportunities and threats}

This meta-capability analyses the existence of opportunities and threats. Generally, threats appear when the ecosystem around the company changes. In relation to customer relationship issues, Alfa Telecom observed the ecosystem movement at the end of the monopoly period. Nowadays, the company had to go through a reorganisation of the organisation in order to operate in a free market. According to the interviewees, Alfa Telecom took a long time to realise that a change was desirable in order to be competitive. In 2002, telecom professionals with expertise and experience in CRM adoption were contracted to launch a CRM project at Alfa Telecom.

People that worked for the company in that period remembered that CRM was a priority for top managers, who were totally committed to the new concepts. A marketing manager interviewed says that the support of top managers at that moment was the only chance to change the existing paradigm in the company. He claims that they had to change organisational processes, and the CRM concepts clashed with Alfa Telecom culture. In 2002, the CRM team faced a hard task, mainly because people were used to work with strong values according to their monopolistic views.

Alfa Telecom has been trying to improve customer relationships since 2002, when the CRM adoption project was launched. The interviewees are unanimous in affirming that Alfa Telecom has really been improving the customer care treatment and there are various technological and behavioural initiatives to improve the company relationship with a customer. On the other hand, they argue about the company's gap in linking customer relationship with employees' individual objectives. Some of the interviewees claim that customer relationship is not a priority issue for the company, because they are concerned with improving sales and minimising cost (mainly in post-sales).

The reduction in land line customers resulting from the advent of mobile phones is a threat to Alfa Telecom. The company also perceives the information system architecture that resulted from legacy system as a threat. Customer data integration is also an issue that could be improved in the company.

According to the interviewees, related to this meta-capability, some customer relationship management processes must constantly be improved in the company: (1) selecting and using IT in order to improve and help staff to attend customers; (2) choosing the employees and partners, it is important to highlight that nowadays companies outsource part of customer services attendance in the call centre; (3) identifying customer segments in order to cater to specific needs and create mechanisms to observe the customer profile in each segment; (4) knowing customers over time; and (5) observing 
customer innovation in the market, in order to aggregate value to build a profitable relationship between both sides of the relationship.

After mapping, creating, recognising and absorbing the new opportunities, the framework indicates that a consolidation phase must take place.

\subsection{To seize opportunities}

First, it is important to delineate customer solution and business model. This process refers to the design and performance of products, and business model employed in order to aggregate customer value (Teece 2007). The person responsible for attending large enterprise customers said that they have established a very close relationship and in order to know the customer enterprise environment, the interviewee goes to sector business meetings.

Second, the company must define its boundaries to manage partners. This activity is responsible for defining which elements form part of and which do not form part of a company's environment. It is very important to know that the company partners can work together in order to maximise their resources and to observe the movements of the competitors. A manager of customer relationship management of Alfa Telecom makes the following metaphor in order to explain the competitive position of the company. He says that the company must be systematically attentive towards the market movements, with the customers and the competitors. According to him, "the managers need to think out of the company scope and pay attention to future needs of the market. It is important to maintain a balance between being reactive and proactive. A company leader may not be the best or innovative in all activities, but may be able to innovate when the competitors launch a new product or service".

Third, it is relevant to define decision making protocols. The definitions of customer relationship rules are crucial so that all organisational employees are able to observe that top managers are concerned with customer relationship. Moreover it helps staff empowerment without losing the consistency in decision. In order to answer market issues, companies have been building a partner network. This network elaborates complex systems, and companies use part of the technological infrastructure of each company. In the case of Alfa Telecom we must consider the shops, the call centre companies, and all companies that offer services to Alfa Telecom.

Teece (2007) claims that an organisation learns from its mistakes. When investments are low and frequent, there are many learning opportunities, but when investments are heavy, the company must avoid mistakes. Some decision making processes implicate risk situations and undervalue rational principles. This kind of mistake is problematic mainly when it involves path dependence phenomenon. One of Alfa Telecom interviewees compares the company with an aircraft carrier. According to him, "this ship needs 20 to $30 \mathrm{~km}$ to get going and 20 to $30 \mathrm{~km}$ to stop. Each kind of manoeuvre must be precise, without any abrupt movement. There are many people inside the ship".

\subsection{To maintain competitiveness}

Competitiveness results from the organisational capability to renew and rearrange the resources that interfere with the customer relationship. Organisational success is linked with technological opportunity and the identification of market opportunity, the business model, and the investments to obtain new critical resources. The success also leads a company through path dependency. According to Teece (2007) the reconfiguration is needed to maintain the evolution and, if necessary, to break unfavourable path dependence.

In order to respond well to customers and technological evolution, companies must achieve a high level of decentralisation. Managers that control different information, in various contexts, and are responsible for different kinds of decision do not have to communicate in order to make a decision. Teece (2007) claims that the only problem is the risk related to the company's ability to continue integration. 
The company strategy must be improved at all times. Managers looking for new combinations to align resources consider cospecialisation, in other words, resources for which it is possible to explore their complementarities.

This meta-capability also highlights company's transfer knowledge mechanism, integration of dispersed know-how and the intellectual property protection issue. When IS people interviewed were asked what they have learnt from the CRM adoption project, they claimed that they have learnt to know how to commit mistakes and how to spend money on IT projects. They said that they spent a lot of money to see consultant Power Point slides and bought any idea related to CRM from consultants that sometimes had no idea of what they were talking about. The manager also argues that they have learned the importance of coaching in which they must understand the project objectives and work with expert partners.

Corporate governance is relevant because intangible assets are critical to the success of the organisation. In this way, new knowledge is crucial as well as the organisational learning mechanisms. Integrating outside knowledge is also important when the company forms part of a network (Teece 2007). The interviewees of Alfa Telecom highlight that in IS projects, the company has various partners to solve the technological question, to source technology and know-how.

Nowadays, as Alfa Telecom feels the impact of its competitors (land line telecom, mobile and substitutes such as VoIP), the holding is planning a new strategy to converge landline and mobile companies. This new market position calls for a CRM project to be a priority. People in the company are motivated to conduct a new CRM project. Moreover, the company administrators must give a financial return to shareholders in a short period of time. This situation maximises the expectations attached to the new CRM project.

At the moment, the company is starting a new cycle of dynamic capabilities. Path dependency is a factor that must be analysed because old mistakes and practices that do not aggregate value must not be repeated. The dynamic capability framework recognises that the past had influenced the company, but committing similar mistakes is not desirable, by any means. In the new Alfa Telecom CRM project new opportunities will appear. It will be important for the company to analyse these opportunities, create priorities and manage them the best way possible to orchestrate this initiative.

\section{FINAL REMARKS}

The objective of this paper was to analyse what are the dynamic capabilities related to a CRM strategy, and how a company can develop them. We discuss CRM dynamic capability theory and propose a framework to analyse Alfa Telecom empirical evidence. We believe that because organisations which adopt a CRM strategy are in a competitive environment, a dynamic model needs to be used to analyse and explain how they can improve their CRM strategy in order to achieve success.

We were concerned with observing the dynamic nature of those capabilities and the extent of their influence on the development of CRM initiatives. We analysed the way companies draw up the configurational path of their organisational resources and competences inside their CRM initiatives.

The theoretical contribution of this paper is to observe CRM as an organisational dynamic capability. Although we have used empirical evidence to show how it is possible to analyse a company's characteristics as elements of dynamic capabilities, it will never be exhaustive or complete. Teece (2007) refers to dynamic capabilities as those that have their own nature, are incomplete, incipient, with nebulous character, and very difficult to implement. This is because dynamic capabilities mean the mobilisation of organisational resources. This process is unique, and results from the company's path dependency. 
The dynamic capability refers to sensing and shaping opportunities, managing threats, combining and recombining specialised company resources in order to respond to market changes, customer needs and the way a company delivers value to shareholders.

Alfa Telecom presented reasons to reorganise itself and the market in which it operates. The "convergence process" resulted from telecom market restructuration, competitors' threats and new demands from final customers. Alfa Telecom is reorganising its resources so that they are based on technological resources. These technological resources are considered the main mechanism for moving other resources (such as organisational structure and human resources). The technological information architecture is considered a technological drive to achieve strategic change in the company.

A highly entrepreneurial management is needed to maintain dynamic capabilities in a company. Managers must sense the actual context and seize opportunities. This kind of management involves recognising problems and tendencies in order to give direction to resources and to draw organisational structure and systems. It is also important to use the technological opportunities to foster alignment with customers' needs. Offering a dynamic capability related to CRM will help a company consider all organisational changes involved in this initiative.

Because a CRM project includes the whole company, the interviewees and the literature highlight that the challenges are related to the company structure, organisational processes, and enterprise culture. Behind each of these questions many past problems of the company are hidden. The technological architecture is also considered a challenge, mainly in traditional companies that have a long history of IT adoption. Traditionally, companies have the advantage of experiencing other IT projects (such as ERP adoption), and may have learnt from this experience. On the other hand, their informational architecture is generally complicated by many legacy systems. As the CRM system must use the organisational data and deal with other systems, the IT team finds other questions to solve due to the inheritance of old IT projects.

Primarily, companies need to develop an organisational culture oriented to customer relationship. The IT team must consider the question of dealing with old systems when implementing CRM systems. In order to be successful with a CRM project, managers must find congruence among various organisational elements such as culture, processes, structure, and technology. All these organisational elements are dynamic, and orchestrating them according to the company's history and current environment is a challenge.

\section{References}

Barney, J. (1991). Firm resources and sustained competitive advantage. Journal of Management, 17 (1), 99-120.

Bhatt, G. D., and Grover, V. (2005). Types of Information Technology Capabilities and Their Role in Competitive Advantage: An Empirical Study. Journal of Management Information Systems, 22 (2), 253-277.

Bohling, T., Bowman, D., LaValle, S., Mittal, V., Narayandas, D., Ramani, G., and Varadarajan, R. (2006). CRM implementation: effectiveness issues and insights. Journal of Service Research, 9 (2), 182-194.

Campbell, A. J. (2003). Creating customer knowledge competence: managing customer relationship management programs strategically. Industrial Marketing Management, 32 (5), 375-383.

Ciborra, C. (2002). The Labyrinths of Information - Challenging the Wisdom of Systems. Oxford.

Coltman, T. (2007). Why build a customer relationship management capability? Journal of Strategic Information Systems, 16(3), 301-320.

Day, G. S. (2000). Managing market relationships. Academy of Marking Science, 28 (1), 24-31.

Dibb, S., and Meadows, M. (2004). Relationship marketing and CRM: a financial services case study. Journal of Strategic Marketing, 12 (2), 111-125.

Eisenhardt, K. M., and Martin, J. A. (2000). Dynamic Capabilities: What are they? Strategic Management Journal, 21 (10/11), 1105-1121. 
Klein, H. K., and Myers, M. D. (1999). A set of principles for conducting and evaluating interpretive field studies in information systems. MIS Quarterly, 23 (1), 67-94.

Gibbert, M., Leibold, M., and Probst, G. (2002). Five Styles of Customer Knowledge Management, and How Smart Companies Use Them to Create Value. European Management Journal, 20 (5), 459-469.

Helfat, C., Finkelstein, S., Mitchell, W., Peteraf, M., Singh, H., Teece, D., and Winter, S. (2007). Dynamic Capabilities - Understanding Strategic Change In Organizations. Blackwell.

Makadok, R. (2001). Toward a synthesis of the resource-based and dynamic-capability views of rent creation. Strategic Management Journal, 22 (5), 387-401.

Maritan, C. A. (2007). Dynamic Capabilities and Organizational Processes. In Helfat, C. et al. Dynamic Capabilities - Understanding Strategic Change in Organizations. Oxford: Blackwell, Publishing.

Orlikowski, W. J., and Baroudi, J. J. (1991). Studying Information Technology in Organizations: Research Approaches and Assumptions. Information Systems Research, 2 (1), 1-28.

Payne, A. (2006). Handbook of CRM: Achieving Excellence in Customer Management. Burlington, MA: Butterworth Heinemann.

Penrose, E. T. (1959). The Theory of the Growth of the Firm. New York: John Wiley.

Peppers, D., and Rogers, M. (2004). Managing Customer Relationships: A Strategic Framework. Hoboken, NJ: Wiley.

Plakoyiannaki, E., and Tzokas, N. (2002). Customer relationship management: A capabilities portfolio perspective. Journal of Database Marketing, 9 (3), 228-237.

Priem, R. L., and Butler, J. E. (2001). Tautology in the Resource-Based View and Implications of Externally Determined Resource Value: Further Comments. The Academy of Management Review, 26 (1), 57-66.

Raman, P., Wittmann, C. M., Rauseo, N. (2006). Leveraging CRM for sales: the role of organizational capabilities in successful CRM implementation. Journal of Personal Selling \& Sales Management, 26 (1), 39-53.

Shoemaker, M. E. (2001). A Framework for Examining IT-Enabled Market Relationships. Journal of Personal Selling \& Sales Management, XXI (2), 177-185.

Stake, R. E. (1995). The Art of Case Study Research. Sage Publications, Thousand Oaks.

Teece, D. J., Pisano, G., and Shuen, A. (1997). Dynamic Capabilities and Strategic Management. Strategic Management Journal, 18 (7), 509-533.

Teece, D. (2007). Explicating Dynamic Capabilities: The Nature and Microfoundations of (sustainable) enterprise performance. Strategic Management Journal, 28 (13), 1319-1350.

Walsham, G. (1993). Interpreting Information Systems in Organizations. New York: Wiley.

Walsham, G. (2006). Doing interpretive research. European Journal of Information Systems, 15 (3), 320330.

Zahra, S. A., Sapienza, H. J., and Davidsson, P. (2006). Entrepreneurship and dynamic capabilities: a review, model and research agenda. Journal of Management Studies, 43 (4), 917-955.

\section{THE IMPACT OF VIRTUAL COMMUNITIES ON E-LOYALTY. A CONCEPTUAL FRAMEWORK}

Krumay, Barbara, WU, Vienna University of Economics and Business, Augasse 2-6, 1090 Vienna, Austria, barbara.krumay@wu.ac.at

Zauner, Christoph, WU, Vienna University of Economics and Business, Augasse 2-6, 1090

Vienna, Austria, christoph.zauner@wu.ac.at

Brandtweiner, Roman, WU, Vienna University of Economics and Business, Augasse 2-6, 1090

Vienna, Austria, roman.brandtweiner@wu.ac.at 